The usual temperature conditions of engine operation, especially those of the C.F.R.-A.S.T.M. knockrating procedure, are such that finely divided carbon is obtained after spark ignition by method $(a)$. It is possible, however, to provide low surface-temperature conditions in which the carbon is obtained by method $(b)$ and appears in the combustion space in the form of lamp black. Recent experiments made accordingly have yielded the somewhat remarkable results shown by the graphs accompanying this letter. It will be seen by reference to the graphs that it was possible to use a mixture 60 per cent weak; the indicated thermal efficiency being then 53 per cent at a usable compression ratio of $11 \cdot 5: 1$, that is, 85 per cent of the air-standard value. The maximum thermal efficiency previously recorded is, so far as known, that of $51 \cdot 6$ per cent or 79 per cent of the air-standard value, obtained by Ricardo for a weak mixture used in a Diesel engine at $15: 1$ compression ratio.

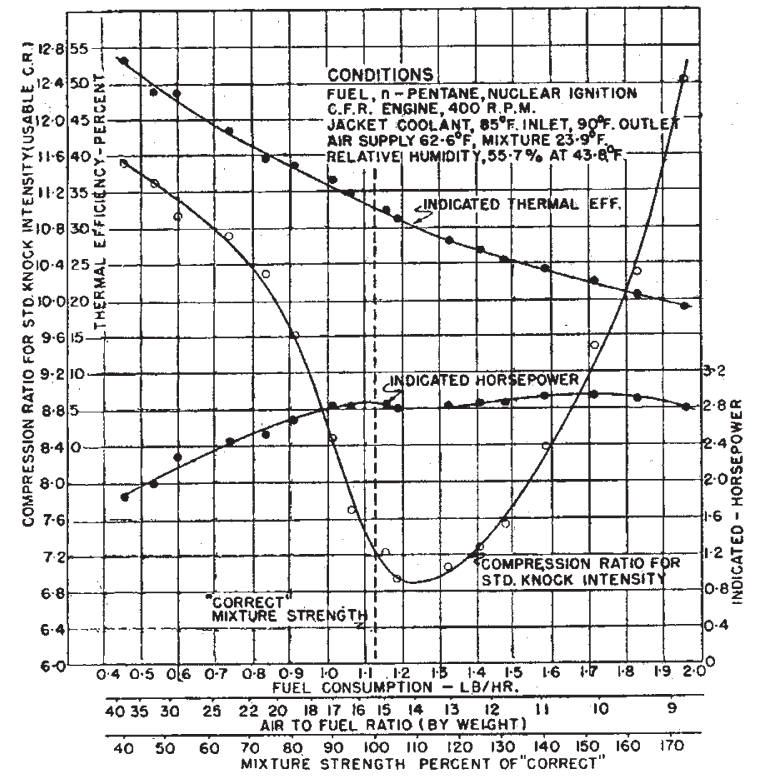

The thermal efficiency was 40 per cent at a usable compression ratio of $10: 1$ and a mixture strength 20 per cent weak, which in usual conditions is the weakest practicable. At the 'correct' mixture, thermal efficiency was 32.5 per cent and the usable compression ratio $7 \cdot 2: 1$, an unusually high value for an engine speed of 400 r.p.m. The minimum value of $\mathbf{6 . 9}$ for the usable compression ratio was obtained for a mixture 9 per cent rich. The value then rose with further increase of mixture strength, becoming 12.4: 1 for a mixture 75 per cent rich. A maximum power output was obtained for the correct mixture, and a second but slightly higher maximum for a mixture 40 per cent rich. Power output varied by approximately 5 per cent only over the mixture range 10 per cent weak to 65 per cent rich.

The 'record' values mentioned above were obtained. without spark ignition. The experiments appear to be of significance in respect of $(a)$ the mechanism of combustion in all types of internal combustion engines and $(b)$ the mechanism of detonation, whether it occur in tubes or in engines. The experiments will be described and discussed elsewhere in greater detail.
The experiments were made in the Department of Mechanical Engineering, University of Toronto, with the co-operation of Prof. E. A. Allcutt, head of the Department.

Defence Research Board, Ottawa.

R. O. KING

E. J. DURand

A. B. Allan

Department of Mechanical Engineering,

University of Toronto. Feb. 21.

${ }^{3}$ King, R. O., Can. J. Research, F, 26, 228 (1948).

\section{The Reticulo-Spinal Apparatus and Rigidity}

IT is commonly held that the vestibulo-spinal apparatus is responsible for maintaining the spastic condition which occurs after decerebration and other operations. Recently, Schreiner, Lindsley and Magoun ${ }^{1}$ and others have suggested that the reticulospinal mechanism is more likely to be implicated. In this connexion the following observations upon an anuran, Bufo marinus, are of interest.

It has been shown ${ }^{2}$ that symmetrical rigidity can be produced in these animals by damage to the midbrain, cerebellectomy, bilateral removal of the eighth nerves or the octavo-lateral areas, or by coronal or sagittal section in the anterior medulla oblongata especially at the level of octavus entrance. The rigidity can be maintained indefinitely after removal of midbrain, cerebellum, both eighth nerves and both octavo-lateral areas. After such operation the residual stump of medulla contains, apart from the usual motor nuclei, little more than a continuous column of small cells. There appears to be no mechanism by which vestibular impulses can play any part, yet the rigidity is maintained.

The continuous column of small cells extends throughout the central nervous system. In the medulla and cord it is intimately associated with the motor cells. In the cord the cells occupy the position described by Brooks and Eccles ${ }^{3}$ for their Golgi type II cells. In the medulla the column occupies the position of the nucleus intercalatus of Staderini and the medial vestibular nucleus, and is giving rise to a superior olive. Throughout, there are numerous longitudinal and crossed connexions. The bulbospinal part of the total system appears to correspond to the reticulo-spinal system of mammals, and is considered the source of the impulses which preserve rigidity.

Anatomical observations point to the probability that the reticulo-spinal apparatus is a ventral, or basal Iaminar, derivative of a general intercalator system, concerned primarily with motor co-ordination at a segmental level, but under the dominance of suprasegmental systems. Histological appearances strongly suggest that the intercalator apparatus serves as a co-ordinating intermediary between all afferent systems on one hand and the motor cells on the other. If so, it serves all the functions commonly ascribed to the motoneuron pool. It would appear appropriate to substitute for this term that of 'reti. culo-motor pool'.

\section{A. A. Abbie}

W. R. ADEY

Department of Anatomy,

University of Adelaide. Feb. 14.

${ }_{1}$ Schreiner, I. H., Lindsley, D. B., and Magoun, H. W., J. Neuro. physiol., 12, 207 (1947).

${ }^{2}$ Abbie, A. A., and Adey, W. R. (in the press).

${ }^{3}$ Brooks, E. McC., and Eccles, J. C., Nature. 159, 760 (1947). 